\title{
O Global como nova era da História
}

\author{
The Global as a new period for History
}

VENGOA, Hugo Fazio. El mundo global: una historia. Bogotá: Ediciones Uniandes, 2013. 135 p.

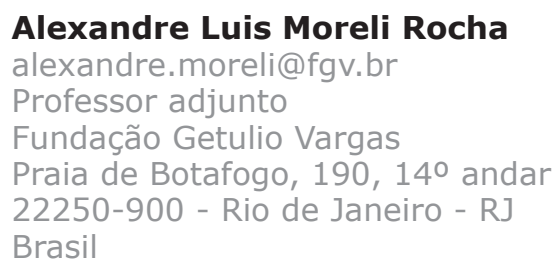

Palavras-chave

História Global; Conceito de história; Contemporaneidade.

Keywords

Global History; Concept of History; Contemporaneity. 
Ao avançar sobre as últimas páginas da primeira obra programática sobre história global produzida na América Latina, ${ }^{1}$ Hugo Fazio Vengoa lembra que "uma grande confusão" ainda reina sobre o tema (VENGOA 2013, p. 113). O professor da Universidad de los Andes, na Colômbia, consciente de que aqueles "que se identificam com essa história não escrevem sobre as mesmas coisas, não utilizam os mesmos argumentos e interagem com diferentes disciplinas" (VENGOA 2013, p. 113), procura oferecer um debate epistemológico, além de seu próprio entendimento do que tem sido a construção de narrativas históricas nos últimos cinquenta anos.

Sem necessariamente remar contra a maré de trabalhos que têm assumido quase que passivamente uma suposta "virada global" das Ciências Humanas, Vengoa recusa uma adesão sem questionamentos. ${ }^{2}$ Apesar de lembrar os ensinamentos de Fernand Braudel de que a história é filha de seu tempo e de que, portanto, as mudanças profundas no "panorama mundial" das últimas décadas fazem com que a disciplina não possa permanecer a mesma, Vengoa ressalta que a consciência e o domínio dos novos processos sociais tornam-se vitais, pois as transformações que as ciências sociais viveram "nas últimas décadas transgrediram inúmeras vezes seus principais enfoques e categorias" (VENGOA 2013, p. xii).

Descrita pelo autor como uma "parada no caminho" (VENGOA 2013, p. ix), a obra aparece assumidamente marcada pela sua trajetória pessoal. Para além de ter sido educado entre os anos 1970 e 1980, nos dois lados da "cortina de ferro" e no chamado Terceiro Mundo, dando-lhe uma perspectiva privilegiada e global do que fora a Guerra Fria, Vengoa diz ter sempre sido atraído por conexões e meta-narrativas ou, em suas próprias palavras, "por temas próprios a um planeta do tamanho de Júpiter, [...] por questões enormes" (VENGOA 2013, p. x). A obra, assim, retoma a definição do global consolidada desde os anos 1990 pelo grupo liderado por Bruce Mazlish (MAZLISH; BUULTJENS 1993), mas a sobrepõe, defendendo que as mudanças provocadas pelo novo processo de globalização, a partir do que chama de "ano-acontecimento" de 1968 , teriam, mais do que apresentado ao historiador novos temas com que trabalhar, inaugurado um novo presente (VENGOA 2013, p. 8).

Mesmo que se leve em consideração as perspectivas lançadas por Mazlish, de que a história global lidaria com a genealogia e com o desenvolvimento da globalização contemporânea através de marcos como a exploração do espaço, os novos sistemas de comunicação, a ameaça nuclear, os problemas ambientais e as companhias multinacionais, por exemplo, para além do abandono do eurocentrismo e de unidades de análise baseadas no Estado Nação, ${ }^{3}$ Vengoa

\footnotetext{
${ }^{1}$ Importante assinalar, entretanto, reflexões como as de Maria Ligia Coelho Prado sobre o assunto (PRADO 2012). 2 No início de 2014, o professor Marc-William Palen, da University of Exeter, fez um simples exercício com motores de busca disponíveis on-line e, apesar de localizar trabalhos evocando o tema desde os anos 1960, identificou uma explosão de títulos a partir de meados da década de 1990 (PALEN 2014). Para além da "global" e da "transnacional", ainda precariamente definidas, alguns debates começam a evocar até mesmo perspectivas "trans-globais" (BERGLUND 2014).

3 Mazlish tem reformado esse entendimento no intuito de reafirmar a especificidade da globalização contemporânea ao chamá-la de Nova História Global e de enfatizar seus aspectos únicos de sinergia, sincronicidade e holismo (MAZLISH 2006, p. 3).
} 
insiste em defender ter o mundo entrado, desde 1968, em uma nova era devido a mudanças em todos os seus processos sociais. A história global fundamentar-se-ia, assim, na globalização, mas iria além. Tratar-se-ia de um esforço de redefinição do que seria o presente vivido pela humanidade, por "cidadãos do planeta", mas também da concepção de mundo como categoria "histórica" ou "social" e, até certo ponto, de uma militância pela criação de uma consciência cosmopolita global (VENGOA 2013, p. xiv-xv, 8).

Enquanto desenvolve tais argumentos, o livro torna-se leitura interessante por quatro razões. A primeira, como já mencionado, por se tratar de uma obra gestada no chamado sul global, ou seja, geográfica e intelectualmente longe do eixo norte atlântico, que tem monopolizado as discussões em torno da história global nas últimas décadas, contribuindo para eliminar a dicotomia entre o norte e o sul acadêmicos.

A segunda identifica-se com o que Vengoa adianta já nas primeiras linhas da Introdução. Trata-se da redação de uma obra de balanço e reflexão, típica da pena de historiadores estabelecidos, mas formados sob influência de escolas de pensamento (como o marxismo ou a area studies) que enfrentam grandes questionamentos teórico-metodológicos quanto ao trato de seus objetos de estudo. O testemunho do autor alinha-se, nessa perspectiva, com outros que a disciplina histórica conhece hoje, como os de Bruce Mazlish ou Akira Iriye, ou conheceu no passado, como os de Marc Bloch e Pierre Renouvin no entre guerras, ou de Edward Thompson e Eric Hobsbawm, após a Segunda Guerra. Todos se assemelhando pelo questionamento epistemológico sobre suas disciplinas e pela busca de uma nova escrita da história.

A terceira razão por destacar que a relativização das questões espaço-temporais não somente revela conexões antes desmerecidas ou esquecidas, mas coloca em choque, ou diálogo, diferentes tradições historiográficas pretendendo rumar em direção ao "global", mas partindo de realidades teórico-metodológicas as mais diversas. O historiador brasileiro, por exemplo, agora não somente deve entender a construção do trabalhismo varguista sob pressão ou influência direta de acontecimentos ocorridos a milhares de quilômetros de distância da nossa costa (FORTES 2014), mas também se preocupar em entender como as narrativas históricas eram ou são construídas nesses distantes locais, a fim de melhor dimensionar sua influência não somente sobre a realidade brasileira mas, sobre a contemporaneidade global.

Finalmente, por tratar-se de uma obra programática, mesmo se classificada pelo autor como "ensaio investigativo exploratório" (VENGOA 2013, p. xvii). Como mencionado, o livro pretende definir contornos de um fenômeno que tem influenciado cada vez mais a escrita da história. Nesse processo, um dos principais destaques é a rejeição ou relativização do eurocentrismo. O fim do processo de descolonização na década de 1970 teria exigido um novo olhar dos cientistas sociais sobre dinâmicas e conexões que teriam nascido ou sido resgatadas do esquecimento provocado por forças que visavam à manutenção de relações assimétricas entre metrópoles e territórios colonizados no mundo. Entre vários efeitos, esse fenômeno provoca a revalorização das meta-narrativas ou, 
como o autor coloca, "a historia global da contemporaneidade" (VENGOA 2013, p. xi). Assim, seria afastada a definição de historia global como a historia da globalização, o que poderia restringir tanto seus propósitos como a compreensão de novos fenômenos que a humanidade experimenta nas últimas décadas.

A obra traz também uma interessante análise da forma como os historiadores, ao menos muitos manuais escolares, constroem imagens de representação do tempo, muitas vezes definindo-o como palco da evolução natural dos acontecimentos. Sofre, assim, dura crítica a presunção de existência "de um tempo social uniforme e indivisível, pressupondo que a cronologia constitui uma progressão neutra e imparcial", tudo isso de forma artificial, sem a ressalva de que se trata apenas de um recurso do qual os historiadores lançam mão em suas análises (VENGOA 2013, p. 83-84). Seria preciso lembrar, ressalta o autor, que, nas diferentes sociedades, existem diferentes ritmos de tempo ou de durações dependendo das dinâmicas sociais às quais se referem (VENGOA 2013, p. 90).

Metodologicamente, para essa nova história, quando não a define somente como novo olhar sobre os fenômenos sociais, Vengoa adota a mesma perspectiva de historiadores como Sanjay Subramanyam, que pregam a história global muito mais como síntese do que como resultado de trabalhos empíricos. Nesse sentido, o autor cita Bartolomé Yun Casalilla para afirmar que "a história global desloca o laboratório do historiador do arquivo para a biblioteca" (VENGOA 2013, p. xviii). O livro, porém, não propõe uma síntese da mencionada contemporaneidade 286 global, mas discute seus elementos componentes. O autor promete seguir adiante, aprofundando sua reflexão sobre os novos marcos de compreensão em obras futuras, como já o fez no recém lançado Los setenta convulsionam el mundo. Irrumpe el presente histórico (2014).

El mundo global trata-se, então, de uma grande obra introdutória de uma série anunciada de sete livros, que pretendem estudar o presente histórico e reforçar o entendimento do autor de que teriam sido as últimas décadas a criar uma era sem precedentes. Como afirma Vengoa, o novo presente "inicia-se no final da década de sessenta e se prolonga até a atualidade mais imediata" (VENGOA 2013, p. xix).

Ainda que introdutória de uma série, a obra estimula no leitor diversas interrogações desde seus primeiros parágrafos sem, entretanto, oferecer respostas claras. Nesse sentido, por exemplo, e questionando o cerne da argumentação do autor de que o mundo global não se resumiria a um mundo que experimenta a globalização, restam diversas dúvidas quanto aos princípios a serem utilizados pelos historiadores para traçar contornos precisos em seus objetivos de estudo quando pretendem lançar mão da história global. Quando evita defini-la como inovação temática, ou quando defende uma revolução espaço-temporal alterando fundamentalmente e tornando sincrônicas as relações humanas ou, finalmente, quando descarta o Estado Nação como unidade de análise, Vengoa não apresenta àquele historiador curioso em trabalhar com tal reflexão alternativas metodológicas precisas para trazer foco e viabilidade às suas pesquisas. 
Outro desafio lançado ao leitor refere-se à busca de Vengoa pela construção de dinâmicas definidoras de uma contemporaneidade de alcance planetário, e não exclusivamente europeu. Quais processos seriam, então, "efetivamente mundiais" e definidores do tempo presente? De fato, em diversos trechos da obra, a centralidade e a matriz europeias parecem não ser negadas. Nesse sentido, a escolha de 1968 como "ano-acontecimento" e como portador de um panorama de reforma da modernidade parece ser um dos mais importantes exemplos (VENGOA 2013, p. 8). As referências a velhas tradições da teoria social do velho continente são também resgatadas quando Vengoa elege o capitalismo como patrocinador da "matriz da globalidade" (VENGOA 2013, p. 39), ou as revoluções burguesas de finais do século XVIII e início do XIX como criadoras das condições "fundamentais para a consolidação das tendências globalizantes" (VENGOA 2013, p. 54). Apesar de sua crítica aos pensadores europeus da sociologia moderna, como Giddens, e de suas ressalvas em afirmar que a modernidade da qual fala não é eurocentrada e nem "se encontra associada com nenhum momento histórico específico nem com nenhuma experiência social em particular" (VENGOA 2013, p. 43-60, 70-72), Vengoa vai desde a eleição do tempo dos "modernos meios de transporte e de comunicação" de finais do século XIX e início do XX como ambiente da "primeira existência real da globalização", até, literalmente, o reconhecimento da modernidade como possuidora de "um importante componente ocidental e capitalista" (VENGOA 2013, p. 39, 55).

A trama lançada por Hugo Fazio Vengoa será desenvolvida nas reflexões que seguirão El mundo global. A espera dos leitores deverá, então, ser recompensada com uma compreensão mais profunda da utilização de 1968 como início de um tempo em que os indivíduos passam a compartilhar um horizonte espaço-temporal sincrônico. Deverão, então, ser expostas de maneira mais consistente as categorias de análise que substituem o entendimento do mundo a partir de um pensamento linear da modernidade e de enfoques unidimensionais da modernização. Deverá surgir, por fim, a defesa (ou definição) de história global não como história da globalização, mas como emergência do local frente à queda das unidades de análise coincidentes com as fronteiras políticas do Estado Nação.

O papel da "Iocalização", como define o autor (VENGOA 2013, p. 29), parece ser fundamental nas reflexões sobre como será possível para os historiadores criar meta-narrativas sem se perder na micro-história e sem que a dicotomia tenha o monopólio da dialética entre o local e o global. Se a globalização, como lembra Henrietta Moore (MOORE 2004, p. 71-72), não teve como resultado a homogenização, mas, ao contrário, por exatamente se alimentar das diferenças, testemunhou culturas locais e diversos modos de vida acomodarem, resistirem ou mesmo alterarem esses novos fenômenos em benefício próprio, deverão ser, então, examinadas as divergências entre a descrição dos fundamentos que moldam as identidades locais e uma suposta história universal, que as transcenderia a fim de concentrar-se nos processos. 


\section{Referências bibliográficas}

BERGLUND, Jeff. Sleuthing the Origins of "Global History". New Global History Forum 2014. Disponível em: http://toynbeeprize.chnm.org/?p=1543. Acesso em: 19 abr. 2015.

FORTES, Alexandre. Os impactos da Segunda Guerra Mundial e a regulação das relações de trabalho no Brasil. Nuevo Mundo Mundos Nuevos, 2014. Disponível em: http://nuevomundo.revues.org/66177. Acesso em: 19 abr. 2015.

MAZLISH, Bruce; BUULTJENS, Ralph. Conceptualizing Global History. Boulder: Westview Press, 1993

MOORE, Henrietta L. Global Anxieties. Concept-Metaphors and Pre-Theoretical Commitments in Anthropology. Anthropological Theory, v. 4, n. 1, p. 71-88, 2004.

PALEN, Marc-William. Call for Papers for the Inaugural Issue JOURNAL OF GLOBAL INDIGENEITY. H-Amstdy 2014. Disponível em: https:// networks.h-net.org/node/2602/discussions/40664/cfp-announcingjournal-global-indigeneity. Acesso em: 19 abr. 2015.

PRADO, Maria Ligia Coelho. América Latina: historia comparada, historias conectadas, historia transnacional. Anuário, Universidad Nacional de Rosário, v. 24, p. 9-22, 2013.

VENGOA, Hugo Fazio. La historia global y su conveniencia para el estudio del pasado y del presente. Historia Critica, edição especial, p. 300-319, novembro 2009.

VENGOA, Hugo Fazio. Los setenta convulsionam el mundo. Irrumpe el presente histórico. Bogotá: Universidade de los Andes, Facultad de Ciencias Sociales, Ediciones Uniandes, 2014. 